\title{
Antineoplastic effect of iodine in mammary cancer: participation of 6-iodolactone (6-IL) and peroxisome proliferator-activated receptors (PPAR)
}

\author{
Carmen Aceves*, Pablo García-Solís, Omar Arroyo-Helguera, Laura Vega- \\ Riveroll, Guadalupe Delgado and Brenda Anguiano
}

Address: Instituto de Neurobiología, Universidad Nacional Autónoma de México, Campus UNAM-Juriquilla, Querétaro, 76230, México

Email: Carmen Aceves* - caracev@servidor.unam.mx; Pablo García-Solís - pablo.garcia@uaq.mx; Omar Arroyo-

Helguera - ELINDMAR@hotmail.com; Laura Vega-Riveroll - riveroll_lauuk@hotmail.com; Guadalupe Delgado - delgado@inb.unam.mx;

Brenda Anguiano - anguiano@inb.unam.mx

* Corresponding author

Published: 6 June 2009

Molecular Cancer 2009, 8:33 doi:10.1 I86/1476-4598-8-33

This article is available from: http://www.molecular-cancer.com/content/8/I/33

(c) 2009 Aceves et al; licensee BioMed Central Ltd.

This is an Open Access article distributed under the terms of the Creative Commons Attribution License (http://creativecommons.org/licenses/by/2.0), which permits unrestricted use, distribution, and reproduction in any medium, provided the original work is properly cited.

\begin{abstract}
Introduction: Studies in mammary cancer demonstrated that moderately high concentrations of molecular iodine $\left(I_{2}\right)$ have a antiproliferative and apoptotic effect either in vivo as in vitro, however the cellular intermediated involved in these effects has not been elucidated.

Methods: Virgin Sprague-Dawley rats were treated with methyl-nitrosourea (MNU: single dose ip, $50 \mathrm{mg} / \mathrm{Kg} \mathrm{bw}$ ) and the participation of arachidonic acid (AA) and PPAR receptors in the antineoplasic effect of $\mathrm{I}_{2}$ where analyzed.

Results: $I_{2}$-treated rats for four weeks exhibited a significant reduction in the incidence (62.5 vs. $100 \%)$ and size $\left(0.87 \pm 0.98\right.$ vs $\left.1.96 \pm 1.5 \mathrm{~cm}^{3}\right)$ of mammary tumors. HPLC analysis showed that tumoral but not normal mammary tissue contained an elevated basal concentration of $A A$ and significantly more AA-iodinated called 6-iodolactone (6-IL) after chronic $\mathrm{I}_{2}$ treatment. Tumors from $\mathrm{I}_{2}$-treated rats showed fewer cells positive to proliferating cell nuclear antigen, lower blood vessel density, as well as decreases in vascular endothelial growth factor, urokinase-type plasminogen activator, and PPAR type alpha (PPAR $\alpha$ ). These same tumors showed increases in the cell death markers, TUNEL-positive cells $(P<0.05)$ and the enzyme caspase- 3 (trend), as well as significant induction of PPAR type gamma (PPAR $\gamma$ ).
\end{abstract}

Conclusion: Together, these data demonstrate that the antineoplasic effect of iodine involves 6IL formation and PPAR $\gamma$ induction.

\section{Introduction}

In recent years, it has become evident that molecular iodine $\left(\mathrm{I}_{2}\right)$ participates in the physiology and/or pathology of extrathyroidal organs like mammary gland, stomach, prostate, etc. [1-3]. In mammary gland $\mathrm{I}_{2}$ but not iodide ( $\mathrm{I}^{-}$) supplementation alleviates human mastalgia and exerts a potent antineoplasic effect on pharmacoinduced mammary tumoral progression in rats [4-7]. In thyroid gland, $\mathrm{I}^{-}$has an apoptotic effect that is mediated by derivatives of arachidonic acid (AA) or eicosapentae- 
noic acid such as 6-iodo-5-hydroxy-8,11,14-eicosatrienoic acid, also called 6-iodolactone (6-IL), or alphaiodohexadecanal, respectively [8-10]. The formation of these iodolipids requires, in addition to iodide uptake by specific transporters, its oxidation by thyroperoxidase (TPO). The oxidized iodine intermediate has not been identified, but one of the candidates is $I_{2}[11,12]$. We reported that mammary glands of virgin rats and MNUinduced tumors take up ${ }^{125} \mathrm{I}_{2}$ by mechanisms independent of the sodium iodine symporter (NIS) or pendrin (PEN) [13]. These findings were corroborated in the human tumoral cell line MCF-7, where we found that ${ }^{125} I_{2}$ is taken up by a facilitated diffusion system and covalently bound to lipids similar to 6-IL in both the presence or absence of peroxidase inhibitors, indicating that the oxidized iodine form $\mathrm{I}_{2}$ is organified in the absence of peroxidases [14]. Our data also shows that cancerous cells are more sensitive than the normal mammary cells to the apoptotic effect of $\mathrm{I}_{2}$, but they are equally sensitive to 6-IL; this suggests the presence of abundant 6 -IL precursor in tumoral cells [15]. 6-IL is formed by the iodination of AA, which is an essential membrane lipid, and elevated AA has been widely implicated in tumoral process [16,17]. Although the cellular mechanism involved in the 6-IL apoptotic effect has not yet been elucidated, we have proposed that the peroxisome proliferator-activated receptors (PPAR) could be the mediator [3]. These ligand-dependent transcription factors are involved in regulating cell cycle control and apoptosis of several cancer cells $[18,19]$. Recently, our laboratory showed that 6-IL is a specific ligand of PPARs with almost 6-fold higher affinity than AA, which is one of the endogenous ligands of these receptors [20]. In the present work we analysed, in an in vivo model, the presence of AA and formation of its 6-IL derivative in normal and tumoral mammary gland after chronic supplement of $\mathrm{I}_{2}$. We also characterized the cellular pathways involved in the antineoplasic effect of $\mathrm{I}_{2}$ treatment.

Our data show that tumoral tissue contains 5-fold more AA and produce 12 times more 6-IL than normal mammary tissue, and that this increase in 6-IL is accompanied by decreases in invasive signals as well as increases in apoptosis indicators. In normal mammary gland from $\mathrm{I}_{2}$ treated rats, these parameters have not shown any changes compared to untreated rats. Together, these data demonstrated that the antineoplasic effect of iodine involves the formation of 6-IL and PPAR $\gamma$ induction.

\section{Materials and methods \\ Animals}

Virgin, female Sprague-Dawley rats, 5 weeks of age, were obtained from the vivarium of the Instituto de Neurobiología, UNAM-Juriquilla. Rats were housed in a temperature-controlled room $\left(21 \pm 1^{\circ} \mathrm{C}\right)$ with a 12 -h light/dark schedule. They were provided with food (Purina rat chow;
Ralston Purina Co., St. Louis, Missouri, USA) and water ad libitum. All of the procedures followed UNAM Animal Care and Use Committee guidelines.

\section{lodine treatment and carcinogenesis induction}

At 5 weeks old, rats were sorted into 2 experimental groups using a randomization process, and iodine treatment was started. The experimental groups were: a) Control and b) $0.05 \% \mathrm{I}_{2}$ in drinking water $\left(\mathrm{I}_{2}\right)$. Distilled water was used for drinking water and for all solutions. A saturating solution of $\mathrm{I}_{2}\left(1.33 \times 10^{-3} \mathrm{M}\right)$ was prepared, and the concentration of $0.05 \%$ was confirmed by titration with sodium thiosulfate (Kenkel, 1994). Treatments were continued until 16 weeks after carcinogen injection. Two weeks after the $\mathrm{I}_{2}$ treatment began, subgroups of rats (control and $\mathrm{I}_{2}$ treatment) were anesthetized with a mixture of ketamine and xylazine (Cheminova, México, $30 \mathrm{mg}$ and 6 $\mathrm{mg}$, respectively, per $\mathrm{Kg}$ bw) and given a single intraperitoneal injection of $50 \mathrm{mg}$ of MNU (Sigma, St. Louis, Missouri, USA) per Kg bw. MNU was dissolved and activated by heating to $50-60^{\circ} \mathrm{C}$ in $0.9 \%$ saline, $\mathrm{pH} 5.0$ [21].

\section{Evaluation of mammary gland carcinogenesis}

Rats were weighed and palpated for tumors every week beginning 4 weeks after and ending 16 weeks after MNU administration. A tumor was defined as a discrete, palpable mass recorded for at least 2 consecutive weeks. Tumor incidence was calculated as the percentage of animals with one or more palpable tumors. Tumor multiplicity was calculated as the average number of tumors per animal in each treatment group. The mean latency of tumor onset for each treatment group was calculated as the mean time interval (in weeks) from MNU injection to the appearance of the first palpable tumor. At the end of the experiment the rats from each group were sacrificed by decapitation. Tumor sizes were measured using a caliper, and the volumes were calculated by the ellipsoid formula [21]. If the tumors reached the ethically maximal size of $3 \mathrm{~cm}^{3}(1.5 \times$ $2.0 \mathrm{~cm})$, rats were anesthetized with the ketamine/xylazine mixture, and the tumors were surgically removed even before the end of the experiment. Normal or tumoral mammary glands were fixed in 10\% neutral buffered formalin or frozen in dry ice and kept at $-70^{\circ} \mathrm{C}$. Blood was collected to determine $\mathrm{T} 3$ circulating levels.

\section{T3 circulating levels}

Serum T3 levels were measured by the homologous RIA method previously described [7].

\section{Histopathological analysis}

Fixed mammary tumors were embedded in paraffin blocks. Sections of 5 - $\mu \mathrm{m}$ thickness were cut from each block and placed on slides that had been treated with 3 aminopropyltriethoxysilane. Sections were deparaffinized in xylene, rehydrated in descending grades of ethanol, and 
stained with hematoxylin and eosin. Tumors were classified according to criteria published by Russo \& Russo [22].

\section{Arachidonic acid (AA) and 6-iodolactone (6-IL) identification}

Normal and tumoral mammary tissues were collected and stored frozen; $500 \mathrm{mg}$ tissue samples were used for neutral lipid extraction according to the procedure described by Boeynaems and Hubbard (1980), and the extracts were evaporated to dryness under a stream of $\mathrm{N}_{2}$ and stored at $-80^{\circ} \mathrm{C}$. Before HPLC (BIO-RAD 2800, Hercules California, USA) analysis, the neutral lipids were dissolved in $100 \% \mathrm{EtOH}$, and a standard curve was constructed with 10-500 nmol of pure AA (Amershan, Arlington Heights, Illinois, USA) or 6-IL dissolved in ethanol. The samples $(100 \mu \mathrm{l})$ were injected into the $\mu$ Bondapak $\mathrm{C}_{18}$ column $(3.9 \times 300 \mathrm{~mm}$; particle size, $10 \mu \mathrm{m}$; WATERS, Milford, Mississippi, USA) maintained at room temperature. Elution was performed with a mobile phase gradient using solution A $\left(\mathrm{CH}_{3} \mathrm{CN}-\mathrm{H}_{2} \mathrm{O} ; 1: 2, \mathrm{vol} / \mathrm{vol}\right)$ and solution $\mathrm{B}$ $\left(\mathrm{CH}_{3} \mathrm{CN}-\mathrm{H}_{2} \mathrm{O} ; 2: 1, \mathrm{vol} / \mathrm{vol}\right)$ at $1 \mathrm{ml} / \mathrm{min}$. Absorption was measured at $206 \mathrm{~nm}$.

\section{Immunohistochemistry of proliferating cell nuclear antigen (PCNA)}

Five- $\mu \mathrm{m}$ sections of mammary tumors from rats with or without $\mathrm{I}_{2}$ treatment were deparaffinized, rehydrated, and subjected to antigen retrieval ( $10 \mathrm{mM}$ sodium citrate) at $80^{\circ} \mathrm{C}$ for 20 minutes. After cooling at room temperature, sections were treated with $0.3 \%$ hydrogen peroxide to block endogenous peroxidase activity. Non-specific binding was blocked with $2 \%$ dried fat-free milk in $20 \%$ fetal bovine serum-PBS solution $\left(1 \mathrm{hr}\right.$ at $\left.37^{\circ} \mathrm{C}\right)$. Sections were incubated at room temperature for $30 \mathrm{~min}$ in a humid chamber with mouse monoclonal anti-rat PCNA, clone PC10 (DakoCytomation, Carpinteria, California, USA), diluted 1:150. Immunocomplexes were visualized by goat anti-mouse-immunoglobulin, peroxidase labeled (EnVi$\operatorname{sion}^{\mathrm{TM}}+$ System, peroxidase, DakoCytomation, Carpinteria, California, USA). Diaminobenzidine (DAB) was used as the chromogen to generate a brown precipitate after reaction with peroxidase. Sections were counterstained with hematoxylin, rinsed, dehydrated, and mounted with Entellan (Merk, Darmstadt, Germany). Cells expressing the antigen were identified by a brown stain over the nucleus. Tumor sections were incubated without either the primary or secondary antibody to test for the specificity of the antibody. PCNA-positive cells were identified by a brown stain over the nucleus. Labeling indices were obtained by counting the number of labeled cells among at least 500 cells per region, and 5 random regions were analyzed.

\section{Quantification of blood vessels}

The protocol described was used to prepare the sections for immunofluorescence. Blood vessels were marked using the anti-mouse antibody coupled to fluorescein isothiocyanate (Alexa Fluor 488; Molecular Probes, Eugene, OR). This antibody stained blood vessels in all samples, as confirmed by dual label immunofluorescence studies with anti-PECAM-1 [23], and the number of stained blood vessels was determined visually ( 5 areas per slide) with a $10 \times$ objective. Images were digitized and evaluated with image-analysis software. Blood vessels were outlined, and their areas were calculated.

\section{Quantification of in situ cell death}

Cell death was detected in formalin-fixed, paraffinembedded tumor sections using the in situ cell death detection kit, fluorescein, POD (Roche Molecular Biochemicals, Mannheim, Germany), which is based on the terminal deoxynucleotidyl transferase-mediated dUTP nick end labeling (TUNEL) method. Sections $(5 \mu \mathrm{m})$ were prepared and treated according to the manufacturer's instructions. DAB was used as the chromogen, and sections were counterstained with hematoxylin. TUNEL-positive cells were identified by a brown stain over the nucleus. Five regions, chosen at random, were analyzed, and labeling indices were obtained by counting the number of labeled cells among at least 500 cells per region and expressed as percentage values.

\section{Caspase-3 activity}

Caspase-3 activity was measured using a standard colorimetric kit (Sigma, St. Louis, MO). Briefly, frozen mammary tumors were homogenized $(1: 2)$ with lysis buffer (50 mM HEPES, pH 7.4, 5 mM CHAPS, $5 \mathrm{mM} \mathrm{DTT,} 4^{\circ} \mathrm{C}$ ). Samples were centrifuged at $16,000 \mathrm{~g}$ for $20 \mathrm{~min}, 4^{\circ} \mathrm{C}$, and supernatants were collected and stored at $-70^{\circ} \mathrm{C}$. Protein concentrations were determined by the Bradford method (BIO-RAD protein assay, Richmond, CA), and $100 \mu \mathrm{g}$ of protein were assayed for caspase activity. The substrate was $200 \mu \mathrm{M}$ DEVD-pNa, which contains the chromophore $p$-nitroanilide ( $\mathrm{pNa}$ ) linked to a synthetic tetrapeptide DEVD (acetyl-Asp-Glu-Val-Asp). Final cocktail $(300 \mathrm{uL})$ were incubated in assay buffer $(20 \mathrm{mM}$ HEPES, pH 7.4, 2 mM EDTA, 0.01\% CHAPS, 5 mM DTT) for $3 \mathrm{~h}$ at $37^{\circ} \mathrm{C}$ with continuous agitation and protected from light in a 96-well plate. Samples were read at $405 \mathrm{~nm}$ in an ELISA reader, and caspase activity was expressed as $\mathrm{nmol}$ of $\mathrm{pNa}$ released/h/mg protein.

\section{Expression of vascular endothelial growth factor (VEGF), urokinase-type plasminogen activator (UPA), and PPAR receptors}

VEGF, uPA, and the alpha and gamma PPAR receptor isoforms were quantified by quantitative real-time PCR (qPCR). Total RNA from normal and tumoral mammary gland from rats with or without $\mathrm{I}_{2}$ treatment was extracted using TRIzol reagent (Life technologies, Inc) according to the manufacturer's instructions. Two micrograms of total RNA was reversed transcribed using the Superscript II sys- 
tem (Invitrogen, Carlsbad, CA). PCR was performed on the sequence detector system Roto-Gene 3000 (Corbett Research, Mortlake, NSW) using SYBR green as a marker for DNA amplification. The reaction was performed with $1 \mu \mathrm{L}$ cDNA template and the qPCR supermix-UDG kit (Invitrogen), using 40 cycles of three-step amplification $\left(94^{\circ} \mathrm{C}\right.$ for $30 \mathrm{~s}, 55-58^{\circ} \mathrm{C}$ for $30 \mathrm{~s}, 72^{\circ} \mathrm{C}$ for $\left.30 \mathrm{~s}\right)$ and the gene-specific primers listed in Table 1. PCR generated only the expected specific amplicon, which was demonstrated in each case by the melting temperature profile (dissociation curve) and by electrophoresis of $5 \mu \mathrm{L}$ of the PCR product through a $2 \%$ agarose gel containing ethidium bromide in TAE buffer. No PCR products were observed in the absence of template. Gene expression was calculated using the Dcycle threshold (Dct) method and normalized to the content of Cyclophilin (Сyc), a nonregulated housekeeping gene [13]. All measurements were performed in triplicate.

\section{Statistical analysis}

The effects of dietary treatments on mammary cancer incidence were analyzed using $2 \times 2$ contingency tables and a one-tail chi-square with Yates' correction test. The effects of treatments on tumor multiplicity, tumor latency, tumor size, caspase-3 activity, PCNA, TUNEL, and vascular area counts were analyzed using the unpaired t test; for the other variables, two-way ANOVA analysis was performed to determine the significance of differences between groups, followed by Tukey's test for the significance of differences among multiple experimental groups. Values with $\mathrm{p}<0.05$ were considered statistically significant.

\section{Results}

Mammary glands were evaluated both macro- and microscopically for the presence of tumors. Various combinations of papillary, cribriform, or comedo mammary carcinomas were detected, and no correlation between histological type of mammary cancer and treatment was observed (data not shown). The effect of long-term $\mathrm{I}_{2}$ treatment on mammary carcinogenesis is summarized in Table 2. Cancer incidence was $37.5 \%$ lower in $\mathrm{I}_{2}$-treated than in control rats, whereas the number of tumors per rat and latency were similar for all groups. As shown in the table 3, body weight and thyroid status remained similar in all groups.

Our first objective was to determine the concentrations of AA and 6-IL in normal and tumoral mammary tissue with and without $I_{2}$ treatment. As shown in the figure 1 , tumoral tissue contains 5-fold more AA than normal mammary gland, and after the $\mathrm{I}_{2}$ treatment, both normal and tumoral tissue contain detectable 6-IL; however, the concentration in tumoral tissue is 12 times greater than in the control.

Figure 2 shows the analysis for cell proliferation in mammary tumors of control and $\mathrm{I}_{2}$-treated rats. Tumors of control rats had significantly more PCNA-positive epithelial cells than tumors of $\mathrm{I}_{2}$-treated rats $(250 \pm 51$ vs $173 \pm 46$ positive cells/500 cells) $\mathrm{p}<0.05 \%$. Moreover, mammary tumors of $\mathrm{I}_{2}$-treated rats were smaller than those of controls $\left(0.87 \pm 0.98\right.$ vs. $\left.1.96 \pm 1.5 \mathrm{~cm}^{3}, \mathrm{p}<0.05 \%\right)$.

To evaluate the effect of $\mathrm{I}_{2}$ treatment on cell death, we used the TUNEL method. Figure 3 shows representative tumor sections of control and $\mathrm{I}_{2}$-treated tumors. Interestingly, mammary tumors of $\mathrm{I}_{2}$-treated rats showed specific zones with numerous TUNEL-positive cells, whereas control tumors have few and disperse TUNEL-positive cells. The mammary tumors of $\mathrm{I}_{2}$-treated rats had a much higher percentage of TUNEL-positive cells $(15 \pm 5.5 \%)$ than the control tumors $(1.0 \pm 1.1 \%)$.

To clarify if the cell death induced by $\mathrm{I}_{2}$ is apoptosis, we measured the activity of the enzyme caspase-3 (figure 4). We found a tendency toward higher caspase- 3 activity (p $=0.246)$ in $\mathrm{I}_{2}$-treated tumors than in control tumors.

To evaluate the effect of iodine on tumoral angiogenesis and invasive potential, we analysed the vasculature area and the expression of VEGF, as well the expression of uPA, respectively. Figures 5, 6, and 7 show that tumors from $\mathrm{I}_{2}$ treated rats exhibited significant decreases in vasculature area as well as lower expression of VEGF and uPA mRNA. They also show that in normal mammary tissue the $\mathrm{I}_{2}$ treatment does not induce any changes in VEGF expression (figure 6) and that uPA expression remains undetectable (figure 7).

The last objective of this study was to analyze the participation of PPAR receptors in the antineoplastic effect of iodine. Figure 8 shows in first time that untreated mammary tumors express significantly higher levels of PPAR $\alpha$ and significantly lower levels of PPAR $\gamma$ than normal mammary gland. The second find is that $\mathrm{I} 2$ treatment exerts a significant decrease in the expression of PPAR $\alpha$ and a sig-

Table I: Oligonucleotides

\begin{tabular}{lllll}
\hline PPAR- $\alpha$ & M88529 & tgtatgaagccatcttcacg & ggcattgaacttcatagcga \\
PPAR- $\gamma$ & AFI56665 & tcaaaccctttaccacggtt & caggctctactttgatcgca & 163 \\
$\beta$-actin & NM-03II44 & gtcccagtatgcctctggtcgtac & ccacgctcggtcaggatcttcatg & 147 \\
VEGF & Nakamura et al, 1996 & gctctcttgggtgcactgga & caccgccttggcttgtcaca & 17I \\
& & & & 563 \\
uPA & & gtggccaaaagactctgagg & caagcgtgtcagcgctgtag & 267 \\
\hline
\end{tabular}


Table 2: Effect of long-term $I_{2}$-treatment on mammary tumorigenesis after 16 weeks of MNU administration.

\begin{tabular}{ccccc}
\hline Treatment & No. of rats with tumors & $\%$ & Tumor latency (weeks) ${ }^{\dagger}$ & Tumors per rat $^{\dagger}$ \\
\hline MNU & $10 / 10$ & 100 & $11.9 \pm 2.8$ & $2.5 \pm 1.7$ \\
I $_{2}$ MNU & $10 / 16^{*}$ & $62.5^{*}$ & $11.6 \pm 1.4$ & $2.0 \pm 0.9$ \\
\hline
\end{tabular}

At 5 weeks of age, rats were treated with $0.05 \% \mathrm{I}_{2}$ in the drinking water. Two weeks later, rats received a single i.p. injection of $\mathrm{MNU}(50 \mathrm{mg} / \mathrm{Kg}$ bw), and the administration of $\mathrm{I}_{2}$ was continued until 16 weeks had elapsed. $\dagger$ indicates mean \pm SD. Asterisk $(*)$ indicates $\mathrm{P}<0.05$ compared to MNU.

nificant increase of the PPAR $\gamma$ isoform in comparison with control tumors. In normal mammary gland; I2 treatment does not modify the expression of either of these receptors.

\section{Discussion}

This report confirms our previous observations that $\mathrm{I}_{2}$ treatment reduces mammary cancer incidence [7], decreases the proliferative rate (PCNA), and induces apoptosis (TUNEL and caspases) in cancerous mammary cells in vitro $[14,15]$ or in vivo without any secondary adverse effect on the thyroid or general health [13]. One interesting effect of $\mathrm{I}_{2}$ treatment observed in these tumors was the generalized reduction in proliferation and vasculature, but the regionalized zones with positive apoptotic signaling (TUNEL) suggest the existence of cell populations with differential $\mathrm{I}_{2}$-sensitivity Although we cannot yet explain this pattern, it is well known that tumors are heterogeneous populations of cells. Studies in our laboratory [15] have shown that cancer cells - either differentiated or not - are more susceptible to the apoptotic effect of $\mathrm{I}_{2}$ than the corresponding normal mammary epithelium (MCF-7 > MDA-MB231 > MCF-12F cells lines, respectively). Indeed, this characteristic pattern of apoptotic zones could account for the lack of significant differences in caspase-3 activity, since it was measured in homogenized pieces of tumors; it may also account for our previous observation that tumor growth resumes if $\mathrm{I}_{2}$ treatment is suspended. [7]. The specific components involved in this $\mathrm{I}_{2}$-sensitivity are not known; however the content of lipids that can be iodinated is an attractive possibility.

The present work demonstrates that tumoral tissue contains significantly higher concentrations of arachidonic

Table 3: Body weight gain and T3 levels after 16 weeks of iodine treatment.

\begin{tabular}{ccc}
\hline Treatment & Body weight gain $(\mathrm{g})$ & $\mathrm{T3}(\mathrm{ng} / \mathrm{dl})$ \\
\hline Control & $154 \pm 15$ & $63.7 \pm 10$ \\
$\mathrm{MNU}$ & $157 \pm 12$ & $67.9 \pm 3$ \\
\hline Control $+\mathrm{I}_{2}$ & $152 \pm 9$ & $63.2 \pm 11$ \\
\hline $\mathrm{MNU}+\mathrm{I}_{2}$ & $150 \pm 16$ & $60.2 \pm 5.6$ \\
\hline
\end{tabular}

acid than normal mammary tissue and that the $\mathrm{I}_{2}$ treatment is accompanied by a 12-fold increase in 6-IL formation. These findings support our earlier hypothesis that the antiproliferative effect of $\mathrm{I}_{2}$ is mediated by the formation of the 6-IL [3]. In thyroid, the apoptotic effect of iodine excess is mediated by $6-\mathrm{IL}$ and/or by iodohexadecanal, both of which are generated by the oxidation and organification of $\mathrm{I}^{-}$by TPO $[9,10]$. In this regard, we reported that in thyroid, excess $\mathrm{I}_{2}$ exerts, as $\mathrm{I}^{-}$, an inhibitory effect on NIS, PEN, TPO, and deiodinase type 1 expression, but without the transient decline in circulating thyroid hormone $(\mathrm{TH})$ levels. This finding indicates that $\mathrm{I}_{2}$ can bind to organic components and thereby inhibit gene expression and also generate TH. Moreover, the finding that $\mathrm{I}_{2}$-treated animals supplemented with methimazole preserve the thyroid gene expression pattern of the WolfChaikoff effect supports the proposals that $\mathrm{I}_{2}$, as an oxidized form of iodine does not need TPO for its organifica-

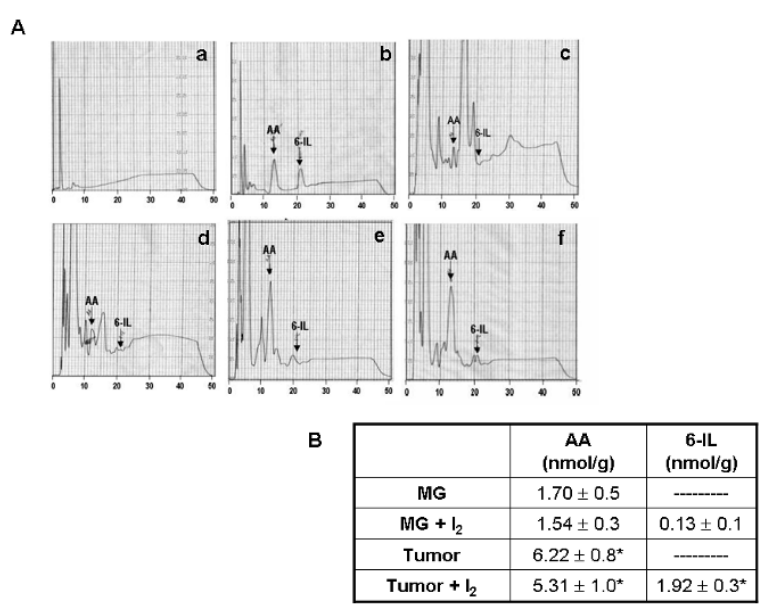

\section{Figure I}

Chromatographic analyzes. Quantification by HPLC of arachidonic acid (AA) content and 6-iodolactone (6-IL) formation in normal (MG) or tumoral (Tumor) mammary glands from rats with or without molecular iodine supplements. A, representative chromatograms; a) base line, b) standards, c) $M G$ control, d) $M G+I_{2}$, e) tumor, f) tumor $+I_{2}$. B, quantification; data are expressed as the mean $\pm S D(n=10)$. Differences between experimental groups were analyzed using a one-way ANOVA and the Tukey-HSD Test. *indicates significant difference from the appropriate control $(p<0.05)$ 

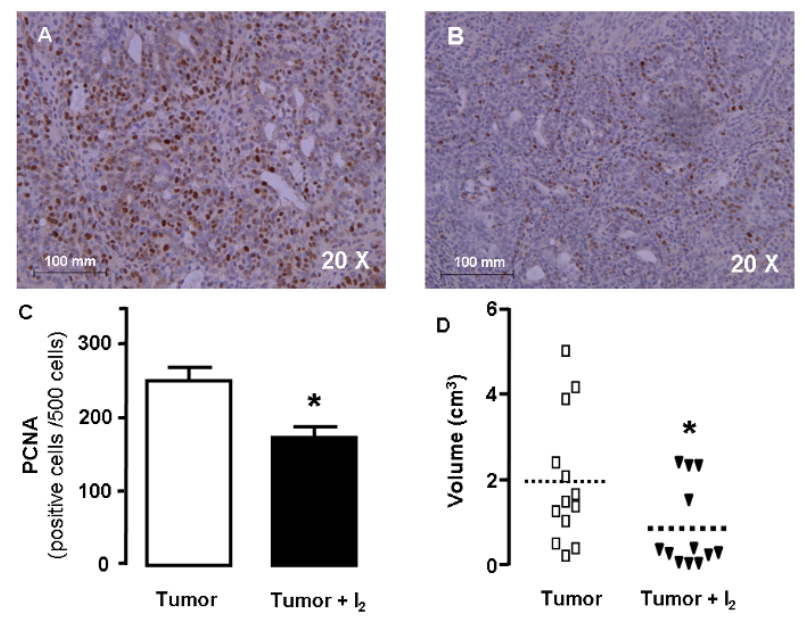

Figure 2

Proliferative rate. Immunohistochemical presence of PCNA-positive cells in tumors from control $(A)$ and $I_{2}$-supplemented rats (B); PCNA-positive cells were revealed with diaminobenzidine (brown stain) and counterstained with hematoxylin (purple stain). C, quantification; $D$, size of tumors (Volume). Differences between experimental groups were analyzed using an unpaired t test. *indicates significant difference from the appropriate control $(p<0.05)$.
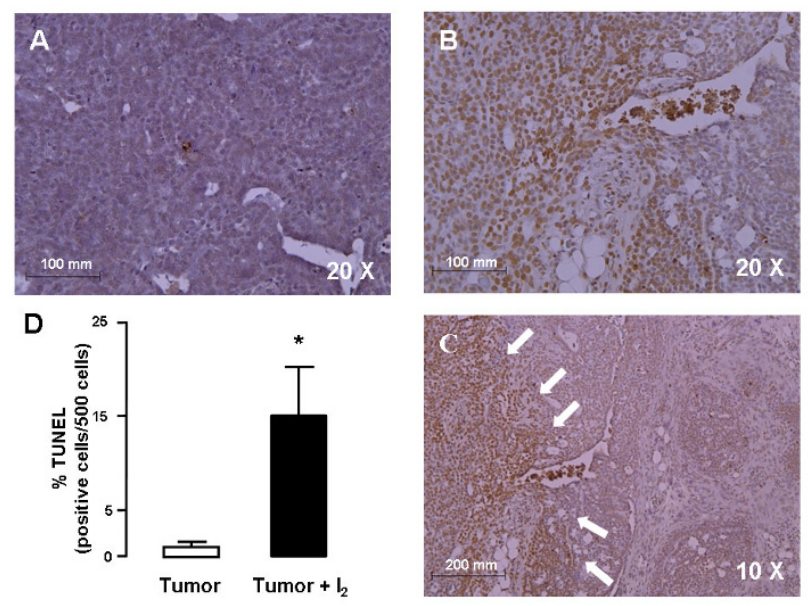

Figure 3

Apoptotic rate. Representative sections of TUNEL-positive cells in tumors from control $(A)$ or $\mathrm{I}_{2}$-treated rats $(B)$, magnification $20 \times$. C, Section of rat tumor treated with $\mathrm{I}_{2}$ that shows an extensive zone of TUNEL-positive cells (white arrows), magnification I0x. TUNEL-positive cells were revealed with diaminobenzidine (brown stain) and counterstained with hematoxylin (purple stain). D, TUNEL-positive cell quantification. The difference between experimental groups was analyzed using an unpaired t test. *indicates significant difference from the control $(p<0.05)$

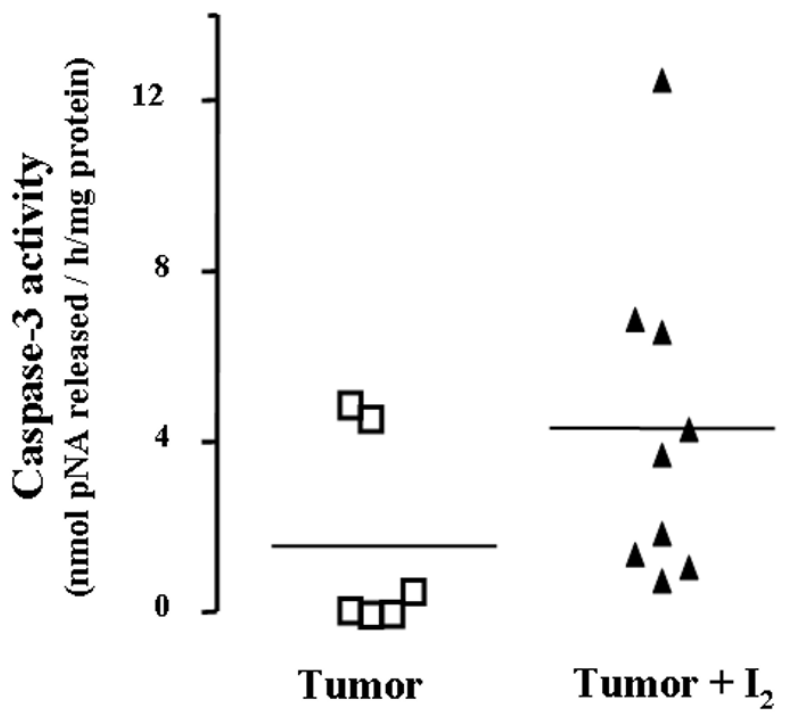

\section{Figure 4}

Caspase-3 activity. Individual tumors from control or $\mathrm{I}_{2}-$ treated rats were assayed; horizontal line represents the mean of each group. Differences between experimental groups were analyzed using an unpaired t test. A tendency toward higher caspase- 3 activity $(P=0.246)$ in $I_{2}$-treated tumors was observed.
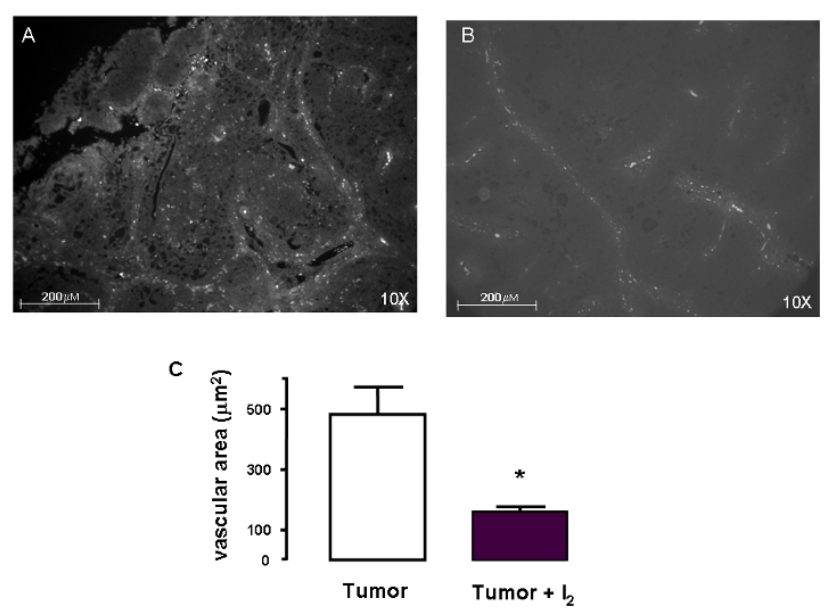

\section{Figure 5}

Vascular area. Immunofluorescence blood vessels in tumors from control $(\mathrm{A})$ and $\mathrm{I}_{2}$-supplemented rats $(\mathrm{B})$. Vessel area was calculated as the total field area positively stained for the vascular marker $\left(\mu \mathrm{m}^{2}\right)$. C, quantification. Differences between experimental groups were analyzed using an unpaired t test. *indicates significant difference from the control $(p<0.05)$ 


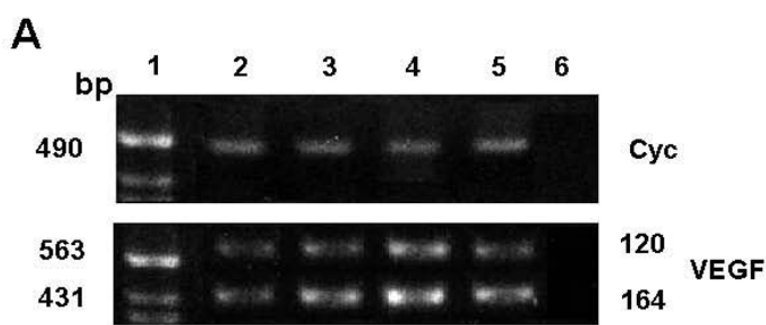

B

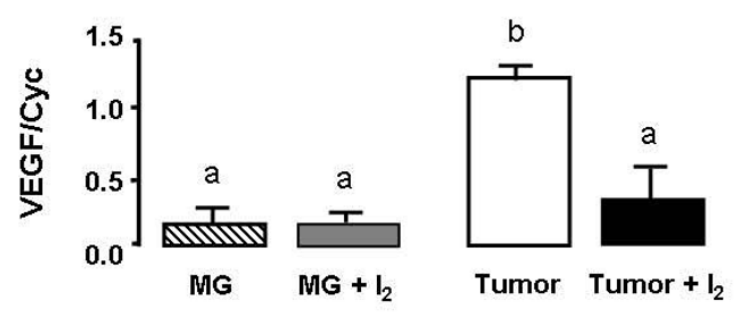

Figure 6

Vascular Endothelial Growth Factor (VEGF) expression. Isoforms of VEGF mRNA in normal (MG) or tumoral (tumor) mammary glands from control or $\mathrm{I}_{2}$-treated rats were measured by the real time PCR method. A. Representative gel of amplicon of Cyclophilin (Cyc) and I20 and I64 isoforms of VEGF mRNA in 2\% agarose gel stained with ethidium bromide. I, ladder; 2, MG; 3, MG + I2., 4, Tumor; 5, Tumor $+\mathrm{I}_{2} ; 6$, all the PCR reagents without RT sample. $B$. VEGF mRNA quantification. Cyclophilin (Cyc) served as internal control and was used to normalize for differences in input RNA. Data are expressed as the mean \pm SD. Differences between experimental groups were analyzed using a one-way ANOVA and the Tukey-HSD Test. Means with different letters are significantly different $(p<0.05)$

tion and that a putative iodine-containing organic compound that mediates these effects is generated [13]. These findings agree with previous data obtained in the MCF-7 cell line, where we found that ${ }^{125} \mathrm{I}_{2}$ is taken up by a facilitated mechanism and that iodinated lipids with a migration similar to that of 6-IL are formed in a process that is not blocked by propylthiouracil (PTU) [14]. It is also interesting that 6 -IL is present in $\mathrm{I}_{2}$-treated normal mammary glands, and the possibility that 6 -IL at this concentration $(0.13 \mathrm{nmol} / \mathrm{g})$ could exert functional effects cannot be dismissed. An analysis investigating this is currently under progress.

Our present data show that $\mathrm{I}_{2}$ treatment significantly reduces PPAR $\alpha$ and increases PPAR $\gamma$ expression, findings that could explain the antineoplasic effect of $\mathrm{I}_{2}$. It is well documented that in mammary cancer cells PPAR $\alpha$ is over-

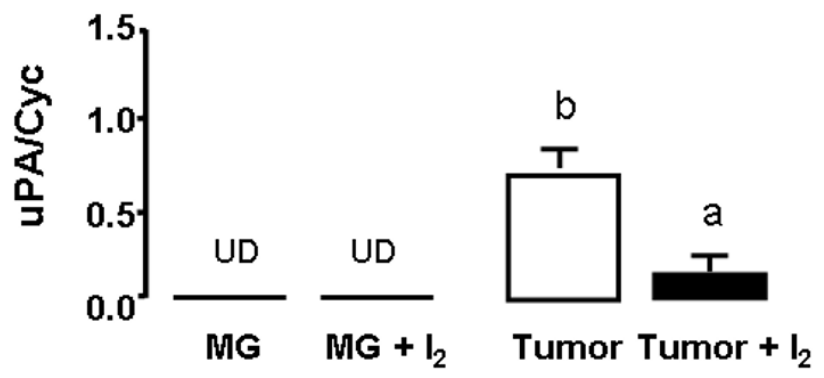

Figure 7

Urokinase Plasminogen Activator (uPA) expression. uPA mRNA in normal (MG) or tumoral (tumor) mammary glands from control or $\mathrm{I}_{2}$-treated rats were measured by the real time PCR method, and Cyclophilin (Cyc) served as internal control. UD, undetectable levels. Data are expressed as the mean $\pm S D$. Differences between experimental groups were analyzed using a one-way ANOVA and the Tukey-HSD Test. Means with different letters are significantly different ( $P$ $<0.05$ )

expressed, and its activation correlates with proliferation $[19,24]$. In contrast, in the rat MNU-mammary cancer model dietary treatment with GW7845, an agonist of PPAR $\gamma$, significantly reduced tumor incidence, tumor number, and tumor weight [25]. Moreover, the significant decrease in vasculature, as well as in VEGF and uPA expression observed in tumors from $\mathrm{I}_{2}$-treated rats, is additional evidence that PPAR receptors participate in the antineoplasic effect of $\mathrm{I}_{2}$. In fact, it has been reported that VEGF is upregulated by PPAR $\alpha$ agonists [24,26], whereas $\mathrm{uPA}$ is inhibited by PPAR $\gamma$ activation [27]. VEGF is a potent mitogen with high specificity for endothelia, and it undergoes alternative splicing generating several isoforms [28]. We showed that isoforms 120 and 164, which are the most involved in angiogenesis, are present in MNUinduced tumors and that $I_{2}$ treatment decreased the expression of both in a similar manner. The inhibition of PPAR $\alpha$ expression might explain this effect, although more complex mechanisms could also be involved. Estrogen is known to induce VEGF expression [29], and recently it was reported that iodine inhibits the expression of several estrogen-responsive genes in MCF-7 cells [30]. Although the detailed mechanism involved in this effect has not been elucidated, PPAR $\gamma$ was shown to exert an inhibitory effect on estrogen-responsive genes via crosstalk with the estrogen receptor binding sites [31]. On the other hand, uPA is a $53-\mathrm{kDa}$ trypsin-like protease that converts the zymogen plasminogen into active plasmin. Although uPA is a relatively specific protease, plasmin acts on a wide variety of protein substrates including metal proteases that destroy the extra cellular matrix (ECM), the degradation of which is a prerequisite for cancer invasion and metastasis [32]. uPA has been used as a specific 
A

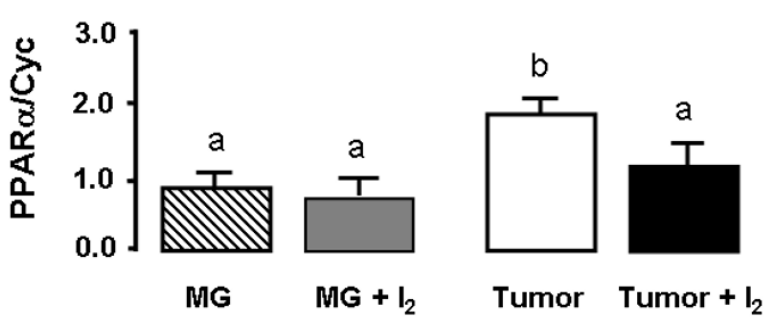

B

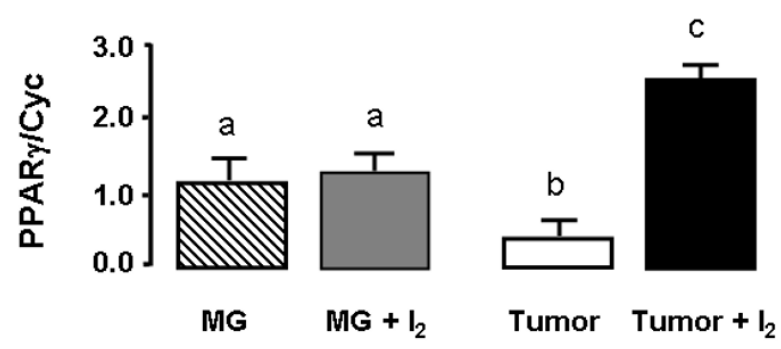

Figure 8

PPAR expression. Isoforms of PPAR mRNA in normal (MG) or tumoral (tumor) mammary glands from control or $\mathrm{I}_{2}$-treated rats were measured by the real time PCR method. A, PPAR type alpha (PPAR $\alpha)$. B, PPAR type gamma (PPAR $\gamma)$. Cyclophilin (Cyc) served as internal control and was used to normalize for differences in input RNA. Data are expressed as the mean $\pm S D$. Differences between experimental groups were analyzed using a one-way ANOVA and the Tukey-HSD Test. Means with different letters are significantly different ( $P$ $<0.05)$

marker for invasiveness in mammary cancer pathology. The presence of high concentrations of uPA in primary breast cancers correlates with a poor prognosis [33]. $\mathrm{I}_{2}$, after its conversion to 6-IL could, on the one hand, trigger the apoptotic cascades and on the other, decrease the invasive potential of cancer cells by inhibiting the expression of metastatic components like VEGF and uPA, which would account for the antineoplastic effect of $\mathrm{I}_{2}$.

In conclusion, these data support our notion that $\mathrm{I}_{2}$ supplement could be an adjuvant in the therapy of mammary cancer, where the high concentration of AA characteristic of tumoral cells serves as substrate to form 6-IL, which in turn triggers the activation of apoptotic and anti-invasive pathways by modulating PPAR receptors.

\section{Competing interests}

The authors declare that they have no competing interests.

\section{Authors' contributions}

CA: have made substantial contributions to conception and design; PGS: carried out some histological and molecular assays, OAH carried out some HPLC analysis, LVR carried out some histological and molecular assays, GD, carried out some HPLC analysis, BA carried out some molecular assay and analysis and interpretation of data. All authors have read and approved the final manuscript.

\section{Acknowledgements}

The authors are grateful to Drs. Alma Chávez-Blanco, Myrna Doris Arrecillas-Zamora, Teresa Andrea Vela-Chávez from INCAN for advice on tumor classification, to Biol. Felipe Ortíz for technical assistance, Pilar Galarza for bibliographic assistance, and Leonor Casanova for academic support. We also thank Nydia Hernández and Lourdes Lara for image advice and Alberto Lara and Omar González for computer assistance. We thank Dr. Dorothy Pless for proof-reading this manuscript. This work was partially supported by grants: PAPIIT-UNAM IN20I 207 and CONACYT 78955.

\section{References}

I. Cann S, van Netten J, van Netten C: Hypothesis: iodine, selenium and the development of breast cancer. Cancer Causes Control 2000, I I(2): | 21 - I 27

2. Venturi S, Donati F, Venturi A, Venturi M, Grossi L, Guidi A: Role of iodine in evolution and carcinogenesis of thyroid, breast and stomach. Adv Clin Path 2000, 4( I): I I- I7

3. Aceves C, Anguiano B, Delgado G: Is iodine a gatekeeper of the integrity of the mammary gland? J Mammary Gland Biol Neoplasia 2005, I0(2): 189-196.

4. Ghent W, Eskin B, Low D, Hill L: lodine replacement in fibrocystic disease of the breast. Can J Surg 1993, 36(5):453-460.

5. Funahashi H, Imai T, Tanaka Y, Tobinaga J, Wada M, Morita T, Yamada F, Tsukamura K, Oiwa M, Kikumori T, et al.: Suppressive effect of iodine on DMBA-induced breast tumor growth in the rat. J Surg Oncol 1996, 6 I(3):209-2I3.

6. Kessler J: The effect of supraphysiologic levels of iodine on patients with cyclic mastalgia. Breast J I0(4):328-336.

7. García-Solís P, Alfaro Y, Anguiano B, Delgado G, Guzman R, Nandi S, Díaz-Muñoz M, Vázquez-Martínez $O$, Aceves C: Inhibition of Nmethyl-N-nitrosourea-induced mammary carcinogenesis by molecular iodine (12) but not by iodide (I-) treatment Evidence that 12 prevents cancer promotion. Mol Cell Endocrinol 2005, 236(I-2):49-57.

8. Dugrillon A, Uedelhoven W, Pisarev M, Bechtner G, Gärtner R: Identification of delta-iodolactone in iodide treated human goiter and its inhibitory effect on proliferation of human thyroid follicles. Horm Metab Res 1994, 26( 10 ):465-469.

9. Pisarev M, Krawiec L, Juvenal G, Bocanera L, Pregliasco L, Sartorio G, Chester $\mathrm{H}$ : Studies on the goiter inhibiting action of iodolactones. Eur J Pharmacol 1994, 258( I-2):33-37.

10. Langer R, Burzler C, Bechtner G, Gärtner R: Influence of iodide and iodolactones on thyroid apoptosis. Evidence that apoptosis induced by iodide is mediated by iodolactones in intact porcine thyroid follicles. Exp Clin Endocrinol Diabetes 2003, I I I (6):325-329.

I I. Zhang L, Sharma S, Zhu L, Kogai T, Hershman J, Brent G, Dubinett S, Huang $M$ : Nonradioactive iodide effectively induces apoptosis in genetically modified lung cancer cells. Cancer Res 2003, 63(16):5065-5072.

12. Smyth $\mathrm{P}$ : Role of iodine in antioxidant defence in thyroid and breast disease. Biofactors 2003, 19(3-4): | $21-130$.

13. Anguiano B, García-Solís P, Delgado G, Aceves Velasco C: Uptake and gene expression with antitumoral doses of iodine in thyroid and mammary gland: evidence that chronic administration has no harmful effects. Thyroid 2007, I 7(9):85 I-859.

14. Arroyo-Helguera O, Anguiano B, Delgado G, Aceves C: Uptake and antiproliferative effect of molecular iodine in the MCF-7 
breast cancer cell line. Endocr Relat Cancer 2006, I3(4): I |47-I I58.

15. Arroyo-Helguera O, Rojas E, Delgado G, Aceves C: Signaling pathways involved in the antiproliferative effect of molecular iodine in normal and tumoral breast cells: evidence that 6iodolactone mediates apoptotic effects. Endocr Relat Cancer 2008, I5(4): 1003-10II.

16. Rillema J, Mulder J: Arachidonic acid distribution in lipids of mammary glands and DMBA-induced tumors of rats. Prostaglandins Med I978, I(I):31-38.

17. Razanamahefa L, Prouff S, Bardon S: Stimulatory effect of arachidonic acid on T-47D human breast cancer cell growth is associated with enhancement of cyclin DI mRNA expression. Nutr Cancer 2000, 38(2):274-280.

18. Berger J, Moller D: The mechanisms of action of PPARs. Annu Rev Med 2002, 53:409-435.

19. Michalik L, Desvergne B, Wahli W: Peroxisome-proliferator-activated receptors and cancers: complex stories. Nat Rev Cancer 2004, 4(I):6I-70.

20. Núñez-Anita RE, Arroyo-Helguera $O$, Cajero-Juárez M, LópezBojorquez $L$, Aceves $C$ : A complex between 6-iodolactone and the peroxisome proliferator-activated receptor type gamma may mediate the antineoplasic effect of iodine in mammary cancer. Prostaglandins and Other Lipid Mediators 2009, 89:34-42.

21. Thompson HJ: Methods for the induction of mammary carcinogenesis in the rat using either 7,12-dimethylbenz[a] antracene or I-methyl-I-nitorosourea. In Methods in mammary gland biology and breast cancer research Edited by: IMaA BB. New York: Kluwer Academic/Plenum Publishers; 2000:19-29.

22. Russo J, Russo I: Atlas and histologic classification of tumors of the rat mammary gland. I Mammary Gland Biol Neoplasia 2000, 5(2): $187-200$.

23. Aranda J, Rivera J, Jeziorski M, Riesgo-Escovar J, Nava G, López-Barrera F, Quiróz-Mercado H, Berger P, Martínez de la Escalera G, Clapp $\mathrm{C}$ : Prolactins are natural inhibitors of angiogenesis in the retina. Invest Ophthalmol Vis Sci 2005, 46(8):2947-2953.

24. Suchanek K, May F, Robinson J, Lee W, Holman N, Monteith G, Roberts-Thomson S: Peroxisome proliferator-activated receptor alpha in the human breast cancer cell lines MCF-7 and MDAMB-23 I. Mol Carcinog 2002, 34(4): I65-I7I.

25. Suh N, Wang Y, Williams C, Risingsong R, Gilmer T, Willson T, Sporn $M$ : A new ligand for the peroxisome proliferator-activated receptor-gamma (PPAR-gamma), GW inhibits rat mammary carcinogenesis. Cancer Res. 1999, 59(22):567I-5673.

26. Biscetti F, Gaetani E, Flex A, Straface G, Pecorini G, Angelini F, Stigliano E, Aprahamian T, Smith R, Castellot J, et al.: Peroxisome Proliferator-Activated Receptor Alpha Is Crucial for Iloprost-Induced in vivo Angiogenesis and Vascular Endothelial Growth Factor Upregulation. J Vasc Res 2008, 46(2): 103-108.

27. Sawai H, Liu J, Reber H, Hines O, Eibl G: Activation of peroxisome proliferator-activated receptor-gamma decreases pancreatic cancer cell invasion through modulation of the plasminogen activator system. Mol Cancer Res 2006, 4(3): 159-167.

28. Houck K, Ferrara N, Winer J, Cachianes G, Li B, Leung D: The vascular endothelial growth factor family: identification of a fourth molecular species and characterization of alternative splicing of RNA. Mol Endocrinol I99I, 5(1 2):1806-I8|4.

29. Nakamura J, Savinov A, Lu Q, Brodie A: Estrogen regulates vascular endothelial growth/permeability factor expression in 7,12-dimethylbenz(a)anthracene-induced rat mammary tumors. Endocrinology 1996, I 37( I 2):5589-5596.

30. Stoddard FR, Brooks A, Eskin B, Johannes G: lodine alters gene expression in the MCF7 breast cancer cell line: evidence for an anti-estrogen effect of iodine. Int J Med Sci 2008, 5(4): $189-196$.

31. Keller H, Givel F, Perroud M, Wahli W: Signaling cross-talk between peroxisome proliferator-activated receptor/retinoid $\times$ receptor and estrogen receptor through estrogen response elements. Mol Endocrinol 1995, 9(7):794-804.

32. Duffy $M$ : Urokinase plasminogen activator and its inhibitor, PAI-I, as prognostic markers in breast cancer: from pilot to level I evidence studies. Clin Chem 2002, 48(8): I | 94- I I 97.

33. Duffy M: Predictive markers in breast and other cancers: a review. Clin Chem 2005, 5 I (3):494-503.
Publish with Biomed Central and every scientist can read your work free of charge

"BioMed Central will be the most significant development for disseminating the results of biomedical research in our lifetime. "

Sir Paul Nurse, Cancer Research UK

Your research papers will be:

- available free of charge to the entire biomedical community

- peer reviewed and published immediately upon acceptance

- cited in PubMed and archived on PubMed Central

- yours - you keep the copyright

Submit your manuscript here:

http://www.biomedcentral.com/info/publishing_adv.asp
BioMedcentral 